\title{
Effect of Solvents on the Product Distribution and Reaction Rate of a Buchwald-Hartwig Amination Reaction
}

\section{Supporting Information}

The reaction mixtures were heated in a $300 \mathrm{~W}$ Emrys Optimizer microwave oven from Personal Chemistry. Emrys Process Vials $2-5 \mathrm{~mL}$ were used as reactors. An infrared detector monitored the temperature of the reaction mixture. In all reactions the temperature of the reaction mixture in the microwave cavity did not exceed the boiling point of the solvents at atmospheric pressure.

The concentration profiles were obtained by HPLC using UV detection at $215 \mathrm{~nm}$. The general procedure for the analysis of the reaction mixtures was as follow: $20 \mu \mathrm{L}$ of the reaction mixture was transferred from the process vial to a sample vial, which contained $1.00 \mathrm{~mL}$ of methanol. The HPLC was operated under isocratic conditions and the mobile phase consisted of acetonitrile and phosphate buffer $(0.025 \mathrm{M}, \mathrm{pH}=8.0,1: 1)$. The method of analysis applied allowed the following components to be detected and quantified: 1, 3, 4, 5, and 6 . The quantification of the five componenets was done by applying Lamberts-Beers law. The extinction coefficient was calculated for each of the five components based on a standard row of four. The components were dissolved in acetonitrile.

The formation of $\mathbf{3}$ and $\mathbf{4}$ was confirmed by ${ }^{1} \mathrm{H}$ and ${ }^{13} \mathrm{C}$ NMR, LC-MS, and HPLC. 5 was confirmed by HPLC, and 6, by HPLC and GC-MS. The spectra obtained were compared to the spectra for the reference compounds.

HPLC: MERCK-HITACHI L-5025 Column Thermostat, L4250 UV-vis Detector, D-6000 Interface, L-6200A Intelligent Pump, As-2000A Autosampler, Colombus column 100 x 4.60 mm, 
$5 \mu, \mathrm{C} 8,100 \mathrm{~A}$. NMR: Bruker Avance $500 \mathrm{MHz}$ two-channel spectrometer. LC-MS: API150ex single quadrupole mass spectrometer. GC-MS: Varian Star 3400 CX, Varian Saturn 2000 equipped with a column from Zebron, ZB-5, $15 \mathrm{~m}, 0.25 \mathrm{~mm}, 0.25$ $\mu \mathrm{m}$. 